Edição especial: 25 anos do Programa de Pós-Graduação em Meio Ambiente e Desenvolvimento Vol. 47, outubro 2018. DOI: 10.5380/dma.v47i0.62441. e-ISSN 2176-9109

\begin{tabular}{l|l}
\hline ISTEMA \\
ELETOONICO \\
DE REVISTAS \\
SER I UFPR
\end{tabular}

\title{
Homenagem dos professores e alunos do Programa de Pós-Graduação em Meio Ambiente e Desenvolvimento - PPGMADE da UFPR ${ }^{1}$
}

Nous, professeurs, étudiants et employés du cours de troisième cycle en environnement et développement de l'Université fédérale de Paraná, au Brésil, souhaitons exprimer notre grand regret pour le décès de Magda Zanoni. Elle était l'idéalisateur principal de notre programme, parmi tant d'initiatives courageuses et fructueuses qu'elle a stimulées tout au long de sa vie.
Nós, professores, alunos e funcionários do curso de Pós-Graduação em Meio Ambiente e Desenvolvimento da Universidade Federal do Paraná, Brasil, queremos manifestar nosso grande pesar pelo falecimento de Magda Zanoni. Ela foi a principal idealizadora do nosso programa, dentre tantas iniciativas corajosas e frutíferas que impulsionou ao longo de sua vida

${ }^{1}$ Lida por Claude Raynaut no dia de sua cremação, Paris, março de 2015. 